\title{
Impact of Teaching Cohesive Devices to Iranian EFL learners: Case of IELTS writing task 2 examination
}

Syed Mojtaba Marashi ${ }^{凶}$

Islamic Azad University, Tehran, Iran

凶email: ames9000@gmail.com

Received:

07 November

2020

Revised:

07 January

2021

Accepted:

26 January

2021

\begin{abstract}
The notion of "textuality" encouraged Halliday and Hasan in 1976 to present their model of discourse analysis through raising questions about whether "cohesion" was a semantic concept or a structural relation, whether a text was a structural unit or not or even if there were semantic or structural relationships within a text. Cohesion was like the glue that unified the meaning within a text through binding the textual elements. Tackling relations of meaning and references in a text was often related to cohesion. A text can be cohesive if its units were bound together with explicit or implicit relations. Cohesion was often defined as the network of lexical, grammatical, and other relations which provide links between various parts of a text. The units of a cohesive text were not just a random set of sentences. Writing section on IELTS was commonly considered one of the most difficult parts of test. The test takers cannot even understand what to do with the tasks provided. They eventually wrote without knowing the expected direction. Therefore, there should be a fast way to equip students well to successfully cope with such hindrances. This research was an action research report of 10 students to make them better understand and answer writing tasks on IELTS test by employing probing techniques as one of test taking strategies. As the result, teaching material about cohesive devices, according to criteria and references to IELTS writing task 2, could help students to understand of their logic on writing proper materials.
\end{abstract}

Keywords: cohesive ties; EFL writing task; IELTS exam; lexical cohesion

\section{INTRODUCTION}

For EFL students, text understanding is of great importance for academic success. Their academic achievements are based on their knowledge of the contents of the textbooks available to their needs. Michael Halliday (1994); one of the linguists credited with the development of systemic linguistics and functional grammar, defines text as any authentic stretch of written or spoken language. According to Halliday (ibid: xiv), the historical study of linguistics first involved studying the morphology of the language followed by studying the meaning of words at the sentence level. Ultimately the goal of such analysis was to find the meaning of the forms of language. However, in Halliday's view, the reverse approach is more meaningful: "A language is 
interpreted as a system of meanings, accompanied by forms through which the meanings can be expressed." Beyond the grammar and lexis of language, understanding the mechanisms for how text is structured is the basis for his work.Cohesion is one aspect of the study of texture, which can be defined as the procedure whereby meaning is diverted into an absorbable amount of discourse "instead of spilling out shapelessly in every possible direction" (Halliday: 1994). Alongside texture, this procedure includes understandings and assumptions regardingthe social context a text dynamically interprets. In the SFL, social context is demonstrated through the register and genre theory (Halliday 1978; Halliday and Hasan 1985; Martin 1992; Christie and Martin 1997). Halliday and Hassan (1976) opine that texts achieve their status and communicative events through the use of cohesive devices. According to them, "the primary determinant of whether a set of sentences do or do not constitute a text depends on the cohesive relationships within and between the sentences, which create texture". De Beaugrande and Dressler (1981: 3) view coherence as one of seven 'standards of textuality', claiming that coherence 'concerns the ways in which the components of the surface text, i.e. the actual words we hear or see, are mutually connected within a sequence. The surface components depend upon each other according to grammatical forms and conventions, such that cohesion rests upon grammatical dependencies'. Therefore, cohesive ties establish a sample of written text's continuity. It is the linguistic mortar that connects the written text together. These authors explain that cohesive relationships within a text are set up where the interpretation of some element in the discourse is dependent on the other.Cohesion refers to the way that a text makes sense syntactically. In the opinion of Olatunde (2002:317), cohesion is interested in relating the internal organization of language to the functions of language, and to the social situation of language.

The relationship between a cohesive item and the item it surmised in a content is alludedas a cohesive tie. Gutwinski (1976) contrasts the various typesof cohesive tie that predominate in writing by Hemingway and James, with Hemingway, he was depending more on lexical cohesion than did James. Halliday and Hasan (1976) provide a detailed coding scheme for analyzing cohesive ties, which takes into account the distance between a cohesive item and the item presupposed. This framework prompted a number of researchers to inquire questions about the relationship between cohesive ties and evaluations of text as coherent or not (Rochester and Martin 1979; Fine et al. 1989), proficient or not (Hartnett, 1986; Olson and Johnson, 1989; Yang 1989), maturing or not (Martin 1983a; Chapman 1983; Nelson and Levy 1987; Pappas 1987), context-dependent or not (Hawkins 1977), and so on. In general, the understanding of patterns of cohesive ties depended in each study on the register, as had been anticipated by Halliday and Hasan (1976: 23): The concept of cohesion can, therefore, be usefully supplemented by that of the register, since the two together effectively define a text. A text is a passage of discourse which is coherent in these two regards: it is coherent concerning the context of the situation, and therefore consistent in the register, and it is coherent concerning itself, and consequently cohesive. As reiterated by Halliday (1994: 339), for a text to be coherent "it must deploy the 
resources of cohesion in ways that are motivated by the register of which it is an instance."

The International English Language Tests System (IELTS) is one of the high stakes tests constructed with the purpose of assessing language abilities of those who intend to continue their academic study in English speaking countries (Alderson, 2000; Douglas, 2000). Recently, some universities in Iran announced their reliance on the IELTS test results, along with other national and international high stakes tests, as partial criteria for acceptance of students in postgraduate programs. The importance and high standard of the test are further accentuated when the pervasive employment of the test score around the world is considered. It shows that the test enjoys the highest standards to become one of the worldwide accepted testing methodologies for assessing learners' capability of using English (IELTS Handbook: 2007).

The test was the result of raising attention to the importance of English for Specific Purpose (ESP) in 1980 (Clapham, 1993). The original form named ELTS aiming to assess learners' ability to use language in different academic areas of physical, medical and social science. Later, under the influence of Munby's (1978) taxonomy, the test has changed to IELTS to ensure the authenticity of the target situation. The idea was that a test should measure language ability, not a specific knowledge (Alderson: 2000).

Kamelifar in 2017 had conducted the similar research for 30 participants at intermediate level who took an IELTS test writing task also in Iran. Meanwhile in this research, the number of participants was only 10 . This condition is pretented as the gap between these researches.

Recently, researchers have given considerable attention to how EFL/ESL learners write and what problems they encounter in writing text. The construct of cohesion is one of the widely explored sub-fields of second language writing. Moreover, by the application of Halliday and Hasan's (1976) framework, a great proportion of the studies about cohesion and coherence in ESL/EFL writing and even in English itself (Jafarpur, 1991, Johns, 1980, Johnson, 1992; Zhang, 2000; Hartnett, 1989 cited in Johnson, 1992) have been done. Although some researchers came to similar findings, the findings of these studies in some cases have been somewhat contradictory. Some have found that there is no difference in the use of CDs in good and weak writings (Johnson, 1992; Zhang, 2000). Others showed that highly rated essays are different from low rated ones in the use of CDs (Jafarpur, 1991). Some researchers proved that highly scored compositions contain more cohesion than low scored ones (Jafarpur, 1991). Furthermore, it is commonly believed that highly scored essays include more lexical collocations than do low scored ones (Johns, 1980; Zhang, 2000). They also held that lexical cohesion is the most commonly used category in both good and weak essays, followed by the conjunction and reference (Johns, 1980; Zhang, 2000).

Coherence, one of the influential features in judging the quality of a writing, has been considered to be a subjective and hazy concept which is hard to learn and teach (Crewe, 1990; Lee, 2002) in spite of the fact that cohesion and coherence being so 
intertwined are not easily distinguished and defined a separate entities. Lee (2002), as a writing teacher and researcher, also believed that the concept of coherence was not definite so that writing teachers had difficulties in teaching and assessing students ${ }^{\text {ce }}$ writing. Meanwhile, some researchers have defined coherence from different perspectives. However, as Grabe and Kaplan (1997, p. 67) stated, "there is little consensus on the matter of an overall definition of coherence." Castro (2004) defines coherence as the link in a text connecting ideas and making the flow of meaningful thoughtsand clear for readers. So, it accounts for the meaningful and logical relationship among elements in a text, which stems from "thematic development, the organization of information, or communicative purpose of the particular discourse" (Kuo, 1995, p.48). In Halliday and Hasan's definition in their book Cohesion in English (1976, p.23), coherence refers to the internal elements of a text, consisting of cohesion and register. They further added that "A text is a passage of discourse which is coherent in these two regards: it is coherent concerning the context of the situation, and therefore consistent in a register, and it is coherent concerning itself, and therefore cohesive".

There is much debate on reasons of this problem that EFL/ESL learners encounter, someclaiming that it is due to the culture/language-specific discourse patterns and different rhetoricalsystems that different languages possess (Kaplan, 1967 \& Chia-Yin, 1991) and some arguing that itstems from lack of knowledge of these links (Bacha \&Hanania, 1980).

Zamel (1983) found the problem in instruction methods the teachers of English use andsuggested that using different strategies is required for teaching these links, and Lee (2002) found theinstruction of cohesive devices effective for improving English learners' writing skill.

Tangkiengsirisin (2010) employed the quantitative approach to explaining linguistic changes orphenomena that occurred in student writing, particularly after the delivery of feedback. The resultsof the study emphasized providing the learners with feedback on their writing with the focus on theiruse of cohesion alongside instruction and found it effective in promotingcohesion in EFL learners'writing skill.

Majdeddin (2010) conducted a study to determine if training courses in writing could cause achange in the learners' use of cohesion in their writing. To narrow down her research, the lexicalcohesion in addition to only one aspect of grammatical cohesion was taken into consideration. She found overt instruction as an effective way for improving the use of lexical cohesive devices in IranianEFL learners' writing.

IELTS includes tests of all four language skills: Listening, Reading, Writing, and Speaking. IELTS tests are held in over 500 centers. IELTS removes any diversity and discrimination to everyone who sits the test, regardless of their nationality. IELTS has a trustable quality and high security due to three reputable organizations which are British Council, IDP: IELTS Australia and the University of Cambridge ESOL Examinations (Cambridge ESOL).Due to the high quality and controlled security procedure, lots of governments and universities rely on it. 
IELTS has given $25 \%$ of its weight-age to Coherence and Cohesion. They are given the highest weight age out of all the resources. Often this is the only reason why people seem to score low marks in the writing and speaking test. Coherence and Cohesion aren't taken seriously by the candidates. It is one of the main reasons why candidates score a low band in writing and speaking task. The IELTS test takers of focusing only on the lexical resources alone.

The reason IELTS writing module is chosen as the focus of this research is many-fold. In the first place, the writing subtest of IELTS seems to be Achilles' heels to every candidate due to many reasons, and many lose scores in writing and consequently gain a low overall band score. It seems necessary that candidates' performance to be scrutinized based on IELTS marking system and under simulated IELTS examination conditions to have a better understanding of the blocking problems causing the yield of low scores. These problems appear to be in direct relation with the conditions under which the test is taken and the writing grading system of IELTS. By applying the standards, pre-designed by IELTS officials, the major issues of Iranian IELTS candidates in writing are expected to be elicited.

It's not enough to give students a list of words and phrases and tell them to start practicing, yet this is often the approach of teachers and students alike. Each cohesive device has nuances in meaning and usage so that memorizing a list would be pointless. Considering 'because' and 'because of'. 'Because' is typically followed by a subject + verb while 'because of' is followed by a noun or noun phrase. Students typically can use 'because' quite easily but 'because of' can cause problems if not practiced.

\section{RESEARCH METHOD}

\section{Participants}

The participants of this study were ten candidates ( 8 male and 2 female) of an IELTS House in the Ahvaz, Khuzestan, Iran. They were selected based on convenience or opportunity sampling procedures. It is because a similar sampling close to that of a real IELTS test is the underlying intention of the researcher. These candidates were all Persian speakers, prepared to take part in a real IELTS test in the future. Due to a low number of respondents, a similar study where a large number of students would participate should be conducted in the future to confirm or refute the present results.

\section{Instrumentation}

The concept of grammatical cohesive devices in Halliday and Hasan's (1976) work was used to develop teaching materials. Cohesive ties fall into five major categories according to them. They are reference made up of personal pronouns, demonstratives, and comparative signals; conjunction whose subcategories are additive, adversative, cause, and temporal; lexical cohesion which consists of reiteration and collocation, ellipses wherein parts of the sentence are left out and substitution wherein words are substituted for other structures.However to make conjunction part more specific and classified, conjunctions were introduced in terms of 
transitional words. They can be simple conjunctions, like and but, or they can be more complex. As cited in ielts.org (IELTS Researchers - Band descriptors, reporting and interpretation, 2012) examiners award a band score for each of four criterion areas: Task Achievement (for Task 1), Task Response (for Task 2), Coherence \& Cohesion, Lexical Resource \& Grammatical Range and Accuracy. The four criteria are equally weighted on the scale of 1 to 9 . The modified analytical style of the International English Language Testing System (IELTS) writing scales were used (Shaw, 2002). Thus, the accessibility of more comprehensive descriptions of written language ability at each band level appears highly advantageous. Some key features such as the qualities of learners' performance, the accuracy of their performance during the task, and distinguishing all the band levels considered as important elements in assessing the process.

Understanding the essential qualities at any different level will help one to comprehend the L2 writing task better (Weigle, 2002; Hawkey and Barker, 2004). Also knowing the exact descriptions were turn out to be one of the compelling features of writing a task which discriminates one level of performance from the other one. Such an account would also allow test-makers to make descriptors more detailed. It would be well received by IELTS raters" (Bridges\&Shaw, 2004).

\section{Data Collection Procedure}

In this study, the candidates were IELTS intending trainees who attended Mock-IELTS. Mock-IELTS (MI) is typically held twice a semester in the alleged institute (every forty-five days), and all IELTS students will have to sit for this test to see the result of five weeks of preparation for the real test. None of the candidates knew their work was going to be analyzed as this information could jeopardize the integrity of this study. Only when the MI was over, everyone was informed of the process to which every individual consented.

On all four MIs, similar procedures as in a real IELTS test were applied. In the same manner, all ID cards were checked. Cell-phones and extra belongings were collected. In the exam area, Farsi was not allowed. Introductory speech on the dos and don'ts of the test was given by the researcher. The test began at a certain time starting with listening and then reading. Finally, with writing, the same amounts of introductory guideline as in IELTS were given. Note that the researcher had sat for the test of IELTS three times, achieving band 8 in all three tries. First the answer sheets, and then the questions' booklets were handed out. The brochures had the same cover as in a real IELTS test. The answer sheets were also the original answer sheet of IELTS writing adopted from IELTS Official Materials (2009). Having finished the tests, all the papers were collected and all the parts of the test except for writing task 2 were excluded.

The first part of the procedure was teaching the participants how to develop task 2. They were also taught an argument article with four different parts (discussed below), which were the introduction, argument, counter-argument and conclusion. Then, they all took an IELTS writing task 2 as a pretest. Subsequently, all the 
participants went through the process of cohesive devices treatment for 5 sessions. In addition, participants needed to learn how to use discourse markers to bind the ideas to each other logically. Participants read the texts and underlined the cohesive devices after the researcher's explanations. When the treatment was over, an immediate posttest in IELTS writing task 2 was conducted. It was a parallel form of the pre-test. The focus of the present study was the IELTS General Writing subtest. In this module, in a real IELTS Test, candidates were given two writing tasks, the second of which was under study in this paper. In Writing Task 2, candidates were given a topic such as the ones below to write about:

\section{WRITING TASK 2}

You should spend about 40 minutes on this task.

Write about the following topic:

Children who are brought up in families that do not have large amounts of money are better prepared to deal with the problems of adult life than children brought up by wealthy parents.

To what extent do you agree or disagree with this opinion?

Give reasons for your answer and include any relevant examples from your own knowledge or experience.

Write at least 250 words.

\section{WRITING TASK 2}

You should spend about 40 minutes on this task.

Write about the following topic:

Some people believe that international tourism has brought enormous benefit to many places. On the other hand, there is concern about its impact on local inhabitants and the environment.

Discuss both views and give your opinion.

Write at least 250 words.

Forty minutes were given to the candidates. They were asked to write at least 250 words. Candidates should write well-organized, relevant, and to the point. They can support their ideas by giving examples or evidence. In this task, candidates confront two types of tasks: a discussion and an argument task. Candidates are required to write an argument essay on the latter using their own opinions and use their own experiences to support the main topic. In the former type, a discussion essay needs to be written where each of the two given views is discussed without the interference of the candidate's personal views. In conclusion, the writer will comment which view is acceptable to him or her. The writer can reasonably accept either one, both, or none of the opinions provided the choice be supported. Candidates receive scores on a Band Scale from 1 to 9. A profile score is reported for each skill. The four individual scores belonging to each language skill are averaged and rounded to produce an Overall Band Score.

In IELTS, each task is assessed independently. Detailed performance descriptors have been developed which describe written performance at the nine 
IELTS bands. Public versions of these descriptors are available on the IELTS website (www.ielts.org). The descriptors are based on the following criteria (for task 2 only):

- Task Response

- Coherence \& Cohesion

- Lexical Resource

- Grammatical Range \& Accuracy

\section{FINDING AND DISCUSSION}

In order to answer the research question "Will the instruction of cohesive devices improve EFL learners' use of cohesive devices on the IELTS writing task 2?" the researcher administered an IELTS writing task 2 for the participants when the treatment was over. To see if there was any statistically significant difference between the mean scores of the participants in pre and posttest in IELTS task, the researcher a paired sample t-test.

All the participants $(\mathrm{N}=10)$

Table 1. Participants' descriptive statistics for IELTS writing task2

\begin{tabular}{llcccc}
\hline \multicolumn{5}{c}{ Paired Samples Statistics } \\
\hline Pair 1 & $\mathrm{N}$ & Mean & $\begin{array}{c}\text { Std. } \\
\text { Deviation }\end{array}$ & SEM \\
& & & & .88 & .28 \\
\cline { 2 - 6 } & Pretest & 10 & 5.3 & .53 & .16 \\
\cline { 2 - 6 } & Posttest & 10 & 6.7 & \\
\hline
\end{tabular}

Table 2. One sample T-test

\begin{tabular}{|c|c|c|c|c|c|c|}
\hline & \multirow[b]{2}{*}{$\mathrm{T}$} & \multirow[b]{2}{*}{ Df } & \multirow[b]{2}{*}{ Sig. (2-tailed) } & \multirow{2}{*}{$\begin{array}{c}\text { Mean } \\
\text { Difference }\end{array}$} & \multicolumn{2}{|c|}{$\begin{array}{c}95 \% \text { Confidence Interval of } \\
\text { the Difference }\end{array}$} \\
\hline & & & & & Lower & Upper \\
\hline $\begin{array}{l}\text { Pretes } \\
\mathrm{t}\end{array}$ & 18.870 & 9 & .000 & 5.3000 & 4.665 & 5.935 \\
\hline $\begin{array}{l}\text { Postte } \\
\text { st }\end{array}$ & 39.419 & 9 & .000 & 6.70000 & 6.3155 & 7.0845 \\
\hline
\end{tabular}

A paired sample t-test was administered to evaluate the effect of taught materials on the cohesive device to see whether there is an improvement on the scores of IELTS writing task 2. According to the statistical results, there is a significant difference between pretest $(M=5.3, S D=.88)$ and posttest $(M=6.7, S D=.53)$. Therefore, it can be claimed that teaching material about how to use cohesive devices properly, according to criteria and references to IELTS writing task 2, will help students to understand of their logic on writing proper materials. As in the writing task 2 marking criteria for a band score 7, it states: "uses a range of cohesive devices appropriately although there may be some under- / over-use". This means that the students understand how to use the cohesive devices but is using too many (in nearly every sentence) or too few. 
Many students who receive a band score 6 or low, will have used far too many, making the writing sound mechanical and not like a native speaker. A high scoring answer of $8+$ will contain a few but well placed cohesive devices as using them with precision and in the correct context counts for more than interesting as many as possible. EFL students must avoid the use of excessive connectors in a single paragraph. With too many linking words, their writing will not sound natural and fluent. It may also distract the examiner while reading the essay. So, they must think carefully whether the connectors are writing match the idea which they are trying to express or not. An alternative to prevent unnecessary connectors is to use pronouns and dependent clauses to fulfill the purpose. Examiners want cohesive devices to be used appropriately, effectively and correctly.

\section{CONCLUSION}

One of the biggest mistakes made by IELTS candidates is using cohesive devices they do not know. They include words like "furthermore" and "consequently," thinking that the IELTS examiner will like it. But if they misuse these words, the examiner will mark them down. Band 5 of the IELTS assessment criteria says: The candidate makes incorrect use of cohesive devices. In other words, if you use cohesive devices incorrectly, you may get no more than a band 5. Appropriate and effective use of cohesive devices also means using them in the right quantity: not too many and not too few. Many IELTS candidates make the mistake of using too many cohesive devices. They throw in lots of cohesive devices, thinking the IELTS examiner will like it. In fact, they will mark you down. Band 7 of the IELTS assessment criteria says: Candidates use a range of cohesive devices appropriately although there may be some under or over-use. In other words, if you use too many or too few cohesive devices, the maximum score you can get is a band 7. To summarize, if you want a Band 8 or above for cohesion, only use cohesive devices when necessary. Use them appropriately, use them correctly and use them effectively.

The surest way to get better at using cohesive devices well is to analyze IELTS writing answers. Finding examples of high scoring sample responses and break them down. How does one paragraph connect to the next? How are the sentences combined? Also every good writer, whether of blogs, novels, magazines or instruction manuals, is a prolific reader. Reading critically and seeking for how paragraphs are connected or contrast is shown and how information is relayed logically. Band 7 or 8 essays show that cohesive devices are used well and effectively. Interestingly, if you look at most Band 8 or 9 essays, there are not that many cohesive devices, when they are used they are very effective. It is not necessary to have them all over the composition, just one or two per paragraph is fine.

Cohesive devices are also essential to use in writing task 1, especially when describing a process and sequencing. Some points to consider are: The cohesive device should connect one sentence to the next, not one supporting idea to the next. If there is a need to connect supporting ideas, link it back to the main idea (e.g., another positive transformation, the most significant change, etc.) Finally, not all sentences need 
cohesive devices. Using linking expressions with every sentence would make writing appear awkward and unnatural.

\section{REFERENCES}

Alderson, J. C. (2000). Assessing reading. Cambridge: Cambridge University Press.

Bacha, N. N. C., \& Hanania, E. (1980). Transitional words: A guide for students of English. The American University of Beirut.

Bridges, G., \& Shaw, S. D. (2004). IELTS writing: Revising assessment criteria and scales (phase 4). Research Notes, 18, 8-12.

Castro, C. D. (2004). Cohesion and the social construction of meaning in the essays of Filipino college students writing in L2 English. Asia Pacific Education Review, 5(2), 215.

Chapman, J. (1983). Cohesion: an overview for the teacher of reading. Australian Journal of Reading, 6(1), 5.

Chapman, L. J. (1983). Reading development and cohesion. Heinemann Educational Books Inc., 70 Court St., Portsmouth, NH 03801.

Chia-Yin, C. (1991). A Training Program for EFL Teachers of Private Language Centers in Taiwan, ROC (Doctoral dissertation, California State University, Chico).

Christie, F., \& Martin, J. R. (1997). Genre and institutions. London: Continuum.

Clapham, C. (1993). Is ESP testing justified? A new decade of language testing research, 257271.

Crewe, W. J. (1990). The illogic of logical connectives. https://doi.org/10.1093/elt/44.4.316

De Beaugrande, R., \& Dressler, W. U. (1981). Einführung in die Textlinguistik (Vol. 28). Tübingen: Niemeyer.

Douglas, D. (2000). Assessing languages for specific purposes. Ernst Klett Sprachen.

Fine, S. B., Cohen, C.,Greenberg, L., Larson, K., Michaelson-Baily, A., Rubinton, P., \& Glick, I. D. (1988). An interdisciplinary psychoeducation program for schizophrenic patients and their families in an acute care setting. Psychiatric Services, 39(3), 277282.

Grabe, W., \& Kaplan, R. B. (1997). The writing course. Beyond Methods: Components of Second Language Education, 172-197.

Gutwinski, W. (1976). Cohesion in literary texts: A study of some grammatical and lexical Features. The Hague: Mouton.

Halliday, M. A. (1978). Language as social semiotics. 
Halliday, M. A. K. (1994). Spoken and written modes of meaning. Media Texts: Authors and readers, $7,51-73$.

Halliday, M. A. K., \& Hasan, R. (1985). Language, context and text. Victoria: Deakin University Press.

Halliday, M. A., \& Hassan, R. (1976). Coherence in English.

Handbook, I. E. L. T. S. (2007). Cambridge, UK: the University of Cambridge, Local Examinations Syndicate

Hartnett, C. G. (1986). Static and dynamic cohesion: signals of thinking in writing. Functional Approaches to Writing. Research Perspectives, London: Frances Pinter.

Hartnett, C. G. (1989). Clues to Mode of Discourse.

Hassan, H. R., \& Halliday, M. (1976). Cohesion in English. P20.

Hawkey, R., \& Barker, F. (2004). Developing a common scale for the assessment of writing. Assessing Writing, 9(2), 122-159.

Hawkins, W. E. (1977). U.S. Patent No. 4,005,566. Washington, DC: U.S. Patent and Trademark Office.

Jafarpur, A. (1991). Cohesiveness as a basis for evaluating compositions. System, 19(4), 459465.

Johns, G. (1981). Difference score measures of organizational behavior variables: A critique. Organizational Behavior and Human Performance, 27(3), 443-463.

Johnson, K. E. (1992). Learning to teach: Instructional actions and decisions of preservice ESL teachers. Tesol Quarterly, 26(3), 507-535.

Kaplan, R. B. (1967). Contrastive rhetoric and the teaching of composition. TESOL quarterly, 1(4), 10-16.

Kuo, H. J. (1995). The (In) Appropiateness and (In) effectiveness of importing communicative language teaching to taiwan. University of Hawai'i Working Papers in English as a Second Language 13 (2).

Lee, J. S. (2002). The Korean language in America: The role of cultural identity in heritage language learning. Language culture and curriculum, 15(2), 117-133. https://doi.org/10.1080/07908310208666638

Majdeddin, K. (2010). Cohesive devices in students' IELTS writing tasks. International Journal of Language Studies, 4(2).

Martin, J. R. (1983). Conjunction: the logic of English text. Micro and macro connexity of texts, $45,1-72$.

Martin, J. R. (1992). English text: System and structure. John Benjamins Publishing. 
Munby, J. (1978). 1978: Communicative syllabus design. Cambridge: Cambridge University Press.

Nelson, K., \& Levy, E. (1987). Development of referential cohesion in a child's monologues. https://doi.org/10.1075/z.lt2.

Olatunde, J. A. (2002). Cohesion as an aspect of textuality in vacancy advertisement'in newspapers. Language meaning and Society. Ilorin: A-Hee Press and Publishing, 312-313.

Olson, M. W., and Johnson, S. (1985). Text type and reader ability: The effects on paraphrase and text-based inference questions. Journal of Reading Behavior, 17(3), 199-214.

Pappas, C. C. (1987). The role of "typicality" in reading comprehension. Understanding readers' understanding: Theory and practice, 129-145.

Rochester, S., and Martin, J. (1979). Crazy Talk: A study of the discourse of schizophrenia speakers. New York: Plenum Press.

Tangkiengsirisin, S. (2010). Promoting cohesion in EFL expository writing: A study of graduate students in Thailand. International Journal of Arts and Sciences, 3(16), 134.

Taylor, L., \& Weir, C. J. (Eds.). (2012). IELTS collected papers 2: Research in reading and listening assessment (Vol. 2). Cambridge University Press.

Weigle, S. C. (2002). Assessing writing. Ernst Klett Sprachen.

Yang, A. W. (1989). Cohesive chains and writing quality. Word, 40(1-2), 235-254.

Zamel, V. (1983). The composing processes of advanced ESL students: Six case studies. TESOL Quarterly, 17(2), 165-188.

Zhang, L. J. (2000). Uncovering Chinese ESL students' reading anxiety in a studyabroad context. Asia Pacific Journal of language in education, 3(2), 31-56. 